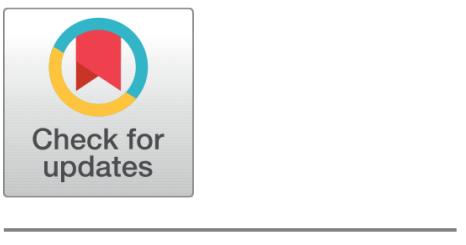

open access

Received: 15.01.2021

Accepted: 02.03.2021

Published: 04.04 .2021

Citation: Teixeira da Silva JA (2021) COVID-19 research and publishing: Advance ambitiously, but cautiously, in 2021. Indian Journal of Science and Technology 14(10): 892-896. htt ps://doi.org/10.17485/IJST/v14i10.92

* Corresponding author.

jaimetex@yahoo.com

Funding: None

Competing Interests: None

Copyright: (c) 2021 Teixeira da Silva. This is an open access article distributed under the terms of the Creative Commons Attribution License, which permits unrestricted use, distribution, and reproduction in any medium, provided the original author and source are credited.

Published By Indian Society for Education and Environment (iSee)

ISSN

Print: 0974-6846

Electronic: 0974-5645

\section{COVID-19 research and publishing: Advance ambitiously, but cautiously, in 2021}

\author{
Jaime A Teixeira da Silva ${ }^{1 *}$ \\ 1 Independent researcher, P. O. Box 7, Ikenobe 3011-2, Kagawa-ken, 761-0799, Japan
}

\section{Abstract}

Objectives: This paper retrospectively reflects on opportunities and risks encountered in 2020 related to publishing COVID-19-related research, and offers perspectives on how researchers should proceed cautiously in 2021. Methods: Based on select literature, the author's perspective, and case studies sourced primarily from PubMed, challenges in publishing COVID-19-related research observed in 2020 and early 2021 are described. Background problems and suggestions for possible solutions are provided. Findings: 2020 was highly transformative, not only for biomedical research as a direct result of a focus on COVID-19, but because many aspects of publishing were challenged. Some concerns that had already been emphasized recently, such as reproducibility, misinformation, or predatory publishing, were amplified in 2020, and carried over into 2021. Open data policies were more encouraged, but in select cases, they were weakly implemented. Applications: Both young and established researchers and academics alike, in their passionate desire to contribute to humanity's advance in understanding COVID-19, need to appreciate several risks and perils that lie within academic publishing.

Keywords: COVID-19; correction of literature; ethics; pandemic; public health; retractions

\section{Society and science were dominated by COVID-19 in 2020}

Like no year in recent memory, 2020 was transformative in so many ways, not only for society, but also for biomedical science research and publishing. Coronavirus disease 2019 (COVID-19), the respiratory disease caused by the SARS-CoV-2 virus, had already, by the end of 2020 , been detected in over 80 million citizens, causing over 1.8 million deaths globally, values that are now about 123 million and 2.7 million, respectively ${ }^{(1)}$. In 2020, according to NCBI's LitCovid, about 85,000 papers related to COVID-19 had been published, values that now sit at $110,934^{(2)}$. For biomedical researchers specializing in COVID-19, or for any reader interested in this work, including the public and media, this volume of information alone is an overwhelmingly large volume to effectively screen for useful and relevant information, and manage. 


\subsection{COVID-19 infodemic and misinformation}

An early analysis of COVID-19 literature indexed in Clarivate Analytics' Web of Science and Elsevier's Scopus revealed that while roughly half of the papers were research articles, there was also a very high volume of editorials, letters to the editor and other opinion papers ${ }^{(3)}$. This large volume and wide selection of manuscript types indicates that academics, the media, policymakers and members of the public had an abundance of information at their disposal. However, they had to be selective from this large mass of information, in an attempt to separate fact from opinion, relying upon this mass of information either for basic information, medical advice, to establish public health policies, informing the public, or for personal use and reflection. In the COVID-19 infodemic, fake news, misinformation and misleading information bred, but some strong counter-measures to detect and reveal misinformation also developed ${ }^{(4)}$.

The release of COVID-19 information that was either factually incorrect or misleading had the ability, especially when transmitted via social media or mass media, to stoke fear, confusion, and reduce trust in a wide range of age groups, and even among health policy makers, although the same conduits of misinformation also established stronger user policies to reduce or eliminate the spread of misinformation ${ }^{(5)}$. One of the most detrimental consequences of such misinformation is reducing trust in COVID-19 vaccines, with a clear link between exposure to misinformation and a concomitant risk of vaccine hesitancy ${ }^{(6)}$. Misinformation about COVID-19 reduced the intent to obtain a vaccine by $6.2 \%$ or $6.4 \%$ among UK and US respondents ${ }^{(7)}$. In Spain, the spread of public health misinformation was fomented by additional factors such as the lack of cognitive authority, or the use of coarse language to discredit people or ideas ${ }^{(8)}$. Rigor in scientific discovery may be hampered by unreliable epidemiologic data, or biases driven by political or economic ideologies, arbitrary selection and/or fear or anxiety ${ }^{(9)}$.

\subsection{Fame are metrics are not necessarily reliable information sources or indicators}

The erroneous notion that highly cited papers in famous or highly ranked medical journals should be automatically accepted as safe sources of information was dispelled by high-profile retractions from two top-ranking medical journals, The Lancet ${ }^{(10)}$ and New England Journal of Medicine ${ }^{(11)}$. In those cases, insufficiently robust peer review, lack of open data policies, and failure by editors to scrutinize raw data prior to publishing "attractive" findings and to accept authors' claims based on blind trust sent a clear message that these weaknesses of academic publishing that had already been emphasized in non-COVID-19 literature, were also true for COVID-19 literature ${ }^{(12)}$. However, not only was peer reviewed COVID-19 literature retracted; preprints, which are "crude" non-peer reviewed documents that are published with the key objective of making potentially useful information quickly available, were also retracted ${ }^{(13)}$. Consequently, poorly vetted, unreliable science and advice both medical or academic -emerged from preprints and peer-reviewed literature. Fortifying the crisis of trust in unreliable COVID-19 literature, the retraction of several preprints has taken place without any verifiable reasons, and absent transparent public explanations ${ }^{(14)}$. Evidently, the risks of publishing poor, unreliable or questionable COVID-19 research or generating unreliable information cannot be eliminated, but these risks can be minimized. Several practical steps to fortifying peer review and publication processes, while minimizing such risks, were suggested: papers should be pre-screened with the assistance of a statistics editor; at least three peer reviewers, preferably as open peer review, should be used; a mandatory open data policy, with strict ethical enforcement, is needed; screening, edits, peer review and online publication should be conducted within short but reasonable time limits to ensure quality, but not victimize authors with tardy and inefficient editorial processing ${ }^{(15)}$.

\subsection{Predatory publishing venues}

Finally, in addition to the risks of unscholarly work in preprints and peer reviewed journals, academics, policy makers and the media should be careful of relying on information that might be published in actual or potential predatory venues ${ }^{(16)}$. While it is not always easy to identify a predatory journal or publisher - which may even appear in famed indexes or databases such as PubMed, Scopus or Web of Science - because predatory characteristics are not always clear-cut or quantifiable ${ }^{(17)}$, academics, policy makers and the media need to develop better screening and selection skills ${ }^{(18)}$, be much more critical of what they read, and not rely blindly on paper's data or conclusions when using, or citing, them. It should not be automatically assumed that indexing platforms and databases are safe sources of COVID-19 literature ${ }^{(19)}$. Caution is also needed when accessing popular sites like Research Gate or Publons in the belief that their popularity is equated with the presence of valid peer-reviewed COVID19 literature ${ }^{(20)}$.

\section{COVID-19 literature: Learning from errors}

In this section, focus is placed on select COVID-19 papers that were corrected or retracted to provide some background, learning points and possible advice, to allow academics that research and publish COVID-19-related literature, to be more 
self-conscious of the perils and challenges that they themselves might unexpectedly face. Of note, while these are actual case studies, the interpretations or advice are somewhat subjective, i.e., they are based on the author's opinion, so readers should be conscientious of this possible bias and or personal influence.

\subsection{Surgisphere, reliability of public data sources, and unfair citations}

As was briefly mentioned above, two high-profile retractions ${ }^{(10,11)}$ drawour attention to the need of editors to not only request the original data at the point of submission, not relying on the "fame" factor of the submitting author or of high-profile authors, and of investigating, where necessary, the validity of the source of data. In the case of the two Mehra et al. retractions, data originated from a data analytics company, Surgisphere, whose website has since disappeared. Data of thousands of patients across six continents were ruled as invalid and unsafe because it was unverifiable ${ }^{(21)}$. Potential risks of using hydroxychloroquine or chloroquine as a treatment for COVID-19 ${ }^{(10)}$, advice that was used by the World Health Organization (WHO) and that was also based on the Surgisphere dataset, was also invalidated ${ }^{(21)}$. Despite this, a Google Scholar on March 1, 2021 search revealed that the two retracted papers continue to be heavily cited, 971 and 804 times, respectively ${ }^{(10,11)}$, although it is very important to appreciate which citations are valid, i.e., based on a critique of the retracted papers, and to differentiate such citations from invalid citations, which are based on the assumption that the findings of those studies continue to be valid. Retracted literature can continue to be cited for various reasons, including the poor or unclear indication of the retracted status of a paper (e.g., on a journal's website or database), access of the unretracted version on science social networks like ResearchGate or Academia.org or on black or pirate open access sites like Sci-Hub, which might not indicate a retracted paper as being retracted ${ }^{(22,23)}$. Journals whose papers have been retracted may be benefitting unfairly by reaping citations to invalidated literature, or to retracted literature that is used to erroneously support claims that are no longer supported by such retracted papers. Consequently, their metrics, like the Clarivate Analytics' journal impact factor or Elsevier/Scopus CiteScore, need to be adjusted downwards and corrected to accommodate for unfair invalid citations to retracted literature ${ }^{(24)}$. In conclusion, when citing a paper on COVID19 , authors and editors should verify its published status on the journal and publisher's original or source website rather than from third party services which may have incorrect or outdated metadata.

\subsection{Expressions of concern and validity of peer review}

Expressions of concern (EoCs) are generally published when an editor or journal might receive concerns about a published paper that were not detected during peer review, but that may require additional evidence involving further investigation. In some cases, through no fault of their own, for example citing a paper that might at some point in a paper's future, be retracted, authors may earn an $\mathrm{EoC}^{(25)}$. Linked to the above retractions ${ }^{(10,11)}$, an EoC in SAGE's Vascular indicates that papers in that journal that were "authored or co-authored by Dr Desai that did not contain significant data or are case reports did not require further critical review" (26), but publishing that editorial note as an EoC, rather than as a simple editorial note, casts perhaps unnecessary and unfounded doubts on all papers by Dr. Desai. In contrast, a clearer EoC related to COVID-19 and vitamin $\mathrm{D}$ indicated concerns about sample size, invalid statistical analyses, claims about the efficiency of vitamin $\mathrm{D}$ that were not supported by the data, and other issues ${ }^{(27)}$, which have yet to be resolved, but which also cast doubt on the robustness of peer review and editorial handling. Academics should thus always view peer review with skepticism and accept that it has limits, and that one of the best ways to circumvent, or minimize, the risks of imperfect peer review, is to try and secure their own peer review and paper quality ${ }^{(28)}$. The integrity of the correction of the literature is also being put at risk through the assignment of EoCs exclusively to html format, which can be easily manipulated or deleted at any time, and the lack of assignment of a $\mathrm{DOI}^{(29)}$.

\subsection{Silent retractions and COPE non-compliant retractions}

A paper received considerable attention for claiming that $5 \mathrm{G}$ technology, as is used in the new and generation of mobile phones, could induce COVID-19 in skin cells ${ }^{(30)}$. After those claims were debunked as unsupported, the paper's PDF file disappeared from public view, in violation of the best practices for retracted papers, as specified by the Committee on Publication Ethics (COPE), which requires retracted papers to indicated the retracted status across each page with a prominent "RETRACTED" stamped across each page. Since the journal, Journal of Biological Regulators \& Homeostatic Agents, is indexed in PubMed ${ }^{(31)}$, this failure to comply with COPE-based ethics requirements raises doubts about the legitimacy of select papers at PubMed. The silent retraction of papers, including preprints ${ }^{(14)}$, related to COVID-19, and the disappearance of public records (PDF files) merits a wider exploration and investigative study. 


\section{Conclusion}

The initial basis for this paper was to provide a response to Gajendran et al., who had indicated that ResearchGate, Academia, Mendeley, Kudos and Publons could be used to garner data and information regarding COVID-19 ${ }^{(20)}$. However, several of those platforms are not necessarily for reliable, accurate or trustworthy information, despite their membership numbers and popularity. In this paper, by emphasizing select aspects of the risks to misinformation caused by social media and the advancement of biased, erroneous or patently incorrect information about COVID-19 on these and other platforms and databases, cautious advice is provided to young researchers, such as early career researchers, and also to seasoned academics, to advance their own research related to COVID-19 passionately, but cautiously, since the risks facing them, their papers and their legacies are in a precarious state of risk if care is not taken.

It is almost self-evident, and obvious, to state that COVID-19 was a central issue in 2020 in the lives of many people around the globe, including researchers and public health workers ${ }^{(32)}$. Biomedical research, including of basic biology and vaccines, work on socio-economic and political influence, and so many other basic and applied aspects of this disease were published in 2020, and LitCovid values suggest that equally high volumes of literature are and will likely continue to be published in 2021 or beyond as COVID-19 may stay with humanity beyond 2021, i.e., the potential endemism of COVID-19 across the globe ${ }^{(33)}$ will continue to spur research and publications on this disease. Academics need to be more savvy about the research and publishing environments in which they exist. They need to appreciate that academic publishing is not only about glamor, fame, ranking, metrics and citations, and that there are real risks not only to their literature, but to their legends, status, careers and networks, any or all of which can be affected if poor decisions are made during the publication process ${ }^{(34)}$. Academics also play a key role in the validation of science, and should be vigilant to prevent the abusive use of ${ }^{(35)}$, or politicization of ${ }^{(36)}$, COVID-19 research. This reality is not restricted to COVID-19 literature.

Academics, like members of the public, are very exhausted from this pandemic, which has affected their personal and professional ways of life, and will continue to do so in $2021^{(37)}$. Rather than letting down their guard and being further negatively impacted by the pandemic, better self-defense mechanisms - including through greater awareness of the risks in academic publishing - to safe-guard themselves against exposure to, and reliance on, poor or incorrect science or misinformation that may exist in social media, preprints or peer-reviewed literature, is needed. Fortified protection and awareness is not equivalent to laziness, although it is perfectly understandable that in these trying times, motivation may be lacking, and that prior research objectives might be more difficult to achieve under constrained work and research environments ${ }^{(38)}$. There are also multiple practical ethical challenges underlying medical aspects of COVID-19 research ${ }^{(39)}$. A greater emphasis on scrutiny and critical evaluation rather than speed, which may have negatively impacted research output in the early months of the pandemic ${ }^{(40)}$, is now needed moving forward into 2021. Finally, great caution is needed about those who are willing to take advantage of the weaknesses or frailties of others, or who are willing to abuse the weaknesses of a health and public services that are under strain, for unfair personal or professional gain ${ }^{(41)}$.

Relying primarily on personal experiences, and focusing on a small subset of COVID-19 papers that are indexed in PubMed, this paper aimed to highlight specific risks and weaknesses so that they might serve as learning points for academics as they advance ambitiously into 2021.

\section{References}

1) John Hopkins University COVID-19 Research Center. Available from: https://coronavirus.jhu.edu/map.html.

2) NCBI/NIH/NLM.LitCovid. Available from: https://www.ncbi.nlm.nih.gov/research/coronavirus/.

3) Teixeira da Silva JA, Tsigaris P, Erfanmanesh M. Publishing volumes in major databases related to Covid-19. Scientometrics. 2021;126(1):831-842. Available from: https://dx.doi.org/10.1007/s11192-020-03675-3.

4) Hartley K, Vu MK. Fighting fake news in the COVID-19 era: policy insights from an equilibrium model. Policy Sciences. 2020;53(4):735-758. Available from: https://dx.doi.org/10.1007/s11077-020-09405-z.

5) Barua Z, Barua S, Aktar S, Kabir N, Li M. Effects of misinformation on COVID-19 individual responses and recommendations for resilience of disastrous consequences of misinformation. Progress in Disaster Science. 2020;8:100119. Available from: https://dx.doi.org/10.1016/j.pdisas.2020.100119.

6) Roozenbeek J, Schneider CR, Dryhurst S, Kerr J, Freeman ALJ, Recchia G, et al. Susceptibility to misinformation about COVID-19 around the world. Royal Society Open Science. 2020;7(10):201199. Available from: https://dx.doi.org/10.1098/rsos.201199.

7) Loomba S, Figueiredo AD, Piatek SJ, Graaf KD, Larson HJ. Measuring the impact of COVID-19 vaccine misinformation on vaccination intent in the UK and USA. Nature Human Behaviour. 2021;5:337-348. Available from: https://doi.org/10.1038/s41562-021-01056-1.

8) Montesi M. Understanding fake news during the Covid-19 health crisis from the perspective of information behaviour: The case of Spain. Journal of Librarianship and Information Science. 2020. Available from: https://dx.doi.org/10.1177/0961000620949653.

9) Szigeti R, Kellermayer D, Trakimas G, Kellermayer R. BCG epidemiology supports its protection against COVID-19? A word of caution. PLOS ONE. 2020;15(10):e0240203. Available from: https://dx.doi.org/10.1371/journal.pone.0240203.

10) Mehra MR, Desai SS, Ruschitzka F, Patel AN. Hydroxychloroquine or chloroquine with or without a macrolide for treatment of COVID-19: a multinational registry analysis. The Lancet. 2020;p. 31324-31330. Available from: https://doi.org/10.1016/S0140-6736(20)31324-6; https://doi.org/10.1016/S0140-6736 (20)31180-6; "expression of concern" https://doi.org/10.1016/S0140-6736(20)31290-3; "retraction" https://doi.org/10.1016/S0140-6736(20)31324-6. 
11) Mehra MR, Desai SS, Kuy S, Henry TD, Patel AN. Cardiovascular disease, drug therapy, and mortality in Covid-19. New England Journal of Medicine. 2020. Available from: https://doi.org/10.1056/NEJMc2021225; https://doi.org/10.1056/NEJMoa2007621; "expression of concern" https://doi.org/10.1056/NEJMe2020822; "retraction" https://doi.org/10.1056/NEJMc2021225.

12) Teixeira da Silva JA. Misinformation in COVID-19 media and literature, with an emphasis on open data policies. Journal of Advocacy, Research and Education. 2020;7(2):25-29.

13) Boschiero MN, Carvalho TA, de Lima Marson FA. Retraction in the era of COVID-19 and its influence on evidence-based medicine: is science in jeopardy? Pulmonology. 2021;27(2):97-106. Available from: https://dx.doi.org/10.1016/j.pulmoe.2020.10.011.

14) Teixeira da Silva JA. Silently withdrawn or retracted preprints related to Covid-19 are a scholarly threat and a potential public health risk: theoretical arguments and suggested recommendations. Online Information Review. Available from: https://doi.org/10.1108/OIR-08-2020-0371.

15) Teixeira da Silva JA, Bornemann-Cimenti H, Tsigaris P. Optimizing peer review to minimize the risk of retracting COVID-19-related literature. Medicine, Health Care and Philosophy. 2021;24(1):21-26. Available from: https://dx.doi.org/10.1007/s11019-020-09990-z.

16) Teixeira da Silva JA. An alert to COVID-19 literature in predatory publishing venues. The Journal of Academic Librarianship. 2020;46(5): 102187. Available from: https://doi.org/10.1016/j.acalib.2020.102187.

17) Teixeira da Silva JA. Is there a clear division between predatory and low-quality journals and publishers? Journal of the Royal College of Physicians of Edinburgh. 2020;50(4):458-459. Available from: https://dx.doi.org/10.4997/jrcpe.2020.427.

18) Gupta L, Gasparyan AY, Misra DP, Agarwal V, Zimba O, Yessirkepov M. Information and misinformation on COVID-19: A cross-sectional survey study. Journal of Korean Medical Science. 2020;35(27):e256. Available from: https://dx.doi.org/10.3346/jkms.2020.35.e256.

19) Bramstedt KA. The carnage of substandard research during the COVID-19 pandemic: a call for quality. Journal of Medical Ethics. 2020;46(12):803-807. Available from: https://dx.doi.org/10.1136/medethics-2020-106494.

20) Gajendran N, Shanthi V, Vendhan AM. Rejuvenation of online research interactive fora during COVID-19. Indian Journal of Science and Technology. 2020;13(47):4603-4605. Available from: https://doi.org/10.17485/IJST/v13i47.2230.

21) Boetto E, Golinelli D, Carullo G, Fantini MP. Frauds in scientific research and how to possibly overcome them. Journal of Medical Ethics. 2020. Available from: https://dx.doi.org/10.1136/medethics-2020-106639.

22) Teixeira da Silva JA. Reasons for citing retracted literature are not straightforward, and solutions are complex. Journal of Applied Physiology. 2020;129 (1):3-3. Available from: https://dx.doi.org/10.1152/japplphysiol.00258.2020.

23) Teixeira da Silva JA, Bornemann-Cimenti H. Why do some retracted papers continue to be cited? Scientometrics. 2017;110(1):365-370. Available from: https://dx.doi.org/10.1007/s11192-016-2178-9.

24) Teixeira da Silva JA, Dobránszki J. Citing retracted papers affects education and librarianship, so distorted academic metrics need a correction. Journal of Librarianship and Scholarly Communication. 2018;6(1):eP2199. Available from: https://dx.doi.org/10.7710/2162-3309.2258.

25) Teixeira da Silva JA. Letter to the editor: Expression of concern. CORR Insights : Preoperative pain sensitization is associated with postoperative pillar pain after open carpal tunnel release. Clinical Orthopaedics and Related Research. 2021;479(1):212-213. Available from: https://doi.org/10.1097/CORR.0000000000001597.

26) Expression of concern. Vascular. Available from: https://doi.org/10.1177/1708538120977849.

27) The PO, Editors. The PLOS ONE Editors. Expression of concern: Vitamin D sufficiency, a serum 25 -hydroxyvitamin D at least $30 \mathrm{ng} / \mathrm{mL}$ reduced risk for adverse clinical outcomes in patients with COVID-19 infection. PLoS ONE. 2020. Available from: https://doi.org/10.1371/journal.pone.0240965.

28) Lakens D. Pandemic researchers - recruit your own best critics. Nature. 2020;581(7807):121. Available from: https://dx.doi.org/10.1038/d41586-020-01392-8.

29) Teixeira da Silva JA. Two disturbing trends about expressions of concern. Medical Journal Armed Forces India;2021. Available from: https://doi.org/10.1016/j.mjafi.2020.12.004.

30) Fioranelli M, Sepehri A, Roccia M, Jafferany M, Olisova OY, Lomonosov KM, et al. 5G technology and induction of coronavirus in skin cells. Journal of Biological Regulators \& Homeostatic Agents. 2020;34(4). Available from: https://doi.org/10.23812/20-269-E-4.

31) NLM Catalog. Journal of Biological Regulators \& Homeostatic Agents. Available from: https://www.ncbi.nlm.nih.gov/nlmcatalog/8809253.

32) Teixeira da Silva JA. ResearchGate preprint (not peer reviewed). 2020. Available from: https://doi.org/10.13140/RG.2.2.19664.74243.

33) Hunter P. The spread of the COVID-19 coronavirus. EMBO Reports. 2020;21(4):e50334. Available from: https://doi.org/10.15252/embr.202050334.

34) Teixeira da Silva JA, Dobránszki J, Al-Khatib A. Legends in science: From boom to bust. Publishing Research Quarterly. 2016;32(4):313-318. Available from: https://dx.doi.org/10.1007/s12109-016-9476-1.

35) Lipworth W, Gentgall M, Kerridge I, Stewart C. Science at warp speed: Medical research, publication, and translation during the COVID-19 pandemic. Journal of Bioethical Inquiry. 2020;17(4):555-561. Available from: https://dx.doi.org/10.1007/s11673-020-10013-y.

36) Kreps SE, Kriner DL. Model uncertainty, political contestation, and public trust in science: Evidence from the COVID-19 pandemic. Science Advances. 2020;6(43):eabd4563. Available from: https://dx.doi.org/10.1126/sciadv.abd4563.

37) Teixeira da Silva JA. Corona exhaustion (CORONEX): COVID-19-induced exhaustion grinding down humanity. Current Research in Behavioral Sciences. 2021;2. Available from: https://dx.doi.org/10.1016/j.crbeha.2021.100014.

38) Magoon R, Ohri R. Compounded research challenges amid the COVID-19 pandemic. Anaesthesia Critical Care \& Pain Medicine. 2020;39(6):689-690. Available from: https://dx.doi.org/10.1016/j.accpm.2020.09.002.

39) Ma XT, Wang YQ, Gao T, He Q, He Y, Yue RS, et al. Challenges and strategies to research ethics in conducting COVID-19 research. Journal of EvidenceBased Medicine. 2020;13(2):173-177. Available from: https://doi.org/10.1111/jebm.12388.

40) Dinis-Oliveira RJ. COVID-19 research: pandemic versus "paperdemic", integrity, values and risks of the "speed science". Forensic Sciences Research. 2020;5(2):174-187. Available from: https://dx.doi.org/10.1080/20961790.2020.1767754.

41) Teixeira da Silva JA. Use of Covid-19 as an illegitimate excuse, or as a scape-goat. Gazeta Médica. 2020;7(4):396-397. Available from: https://doi.org/10.29315/gm.v7i4.409. 